\title{
An approach through the looking-glass
}

\author{
WAYNE A. HERSHBERGER \\ Northern Illinois University, DeKalb, Illinois
}

\begin{abstract}
Forty food-deprived cockerel chicks were tested individually in a straight runway containing a familiar food cup that moved when the chicks moved. The food cup always moved in the same direction as the chick: For 20 experimental chicks it moved twice as far as the chick; for 20 control chicks it moved half as far. In Lewis Carroll's (1898/1926) picturesque terminology, the experimental chicks were tested in Alice's "room through the looking-glass," in which, in order to approach the food cup, they had to "walk the other way." Although the control chicks performed well, the experimental chicks evinced the runway behavior that characterizes positive feedback: They persistently chased the food cup away. This means that the spatial polarity of visual feedback is critical and implies that an ordinary approach response is but an automatic (closed-loop) realization of an intended visual perception.
\end{abstract}

Powers (1973a, 1973b, 1978; Powers, Clark, \& McFarland, 1960a, 1960b) has asserted that organisms are closed-loop mechanisms that realize their intentions by means of negative feedback. An implication of this thesis is that it should be possible to disable an organism simply by reversing the spatial polarity of its feedback. The experiment reported below tested this hypothesis.

A closed-loop system with positive feedback evinces a characteristic self-perpetuating runaway behavior. The positive feedback loop operates as the proverbial vicious circle, driving the value of the "controlled" variable farther and farther from its intended value. Although there appear to be numerous examples of such runaway behavior in the experimental literature, distributed across a variety of species, including insects (von Holst \& Mittelstaedt, 1950), fish, amphibians, rodents (Sperry, 1951), and man (Smith \& Molitor, 1969; Yarbus, 1962), these examples are not altogether compelling as evidence because (1) the runaway behaviors described involve reflexive as opposed to nonreflexive (instrumental) responding, and (2) the experimental methods involved physical alteration of the subjects, either mechanically or surgically.

In the present experiment an altered environment, rather than an altered organism, was used to test the prediction that instrumental behaviors of an organism are seriously impaired by a simple polarity reversal. Hungry young chicks with very limited locomotor experience were tested for their ability to approach a food dish in a straight runway in which the chick's visible environment, including the food cup, moved in the same direction, and twice as far, as did the chick. In Lewis Carroll's (1898/1926) picturesque terminology, the chicks were tested in Alice's

This paper reports research from the author's doctoral dissertation, which was supported by Public Health Service Fellowship MF-13, 198 from the National Institutes of Health, Public Health Service, and was conducted under the kind and able direction of the late Maurice P. Smith in the Department of Psychology at the University of Colorado.

Requests for reprints should be sent to Wayne A. Hershberger, Department of Psychology, Northern Ilinois University, DeKalb, IL 60115. "room through the looking-glass," wherein they could approach the food cup only by walking "the other way," The question is, would they "walk the other way," or would they merely run away after the receding food cup, as the closed-loop thesis predicts?

Specifically, 40 hungry 4-day-old cockerel chicks were tested individually in a straight runway containing a food cup from which they had been trained to eat. The food cup was moved along the length of the alleyway in the same direction in which the chick moved. For half the chicks (experimentals) the cup moved twice as far as the chick; for the remaining half (controls) the cup moved

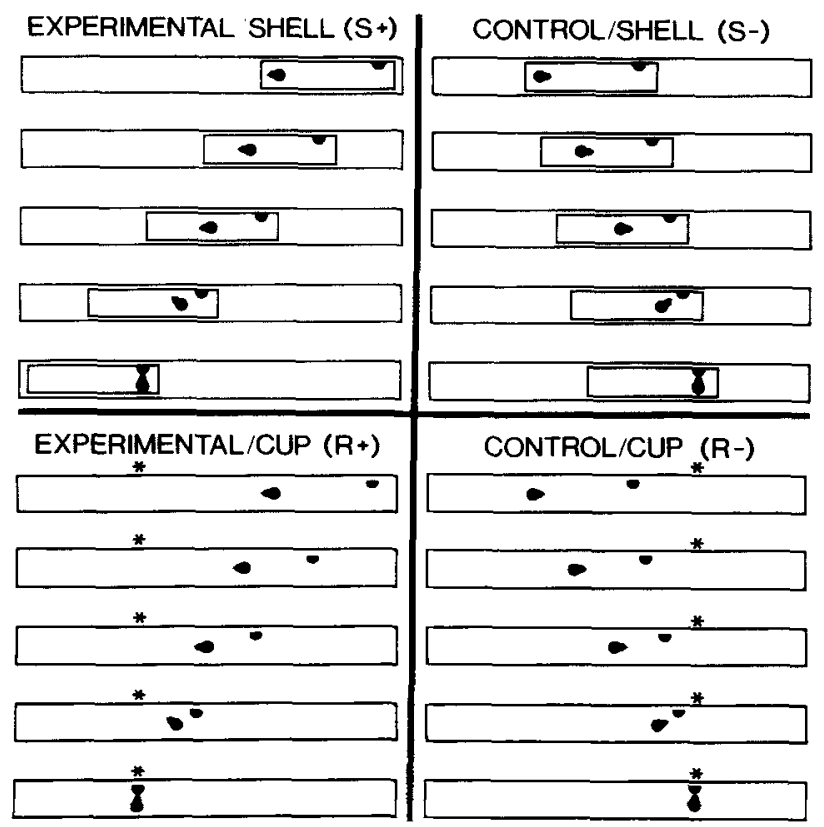

Figure 1. The four test conditions. Each is illustrated by means of five diagrams representing successive positions of a successful chick approaching the food cup. A piece of glitter tape was attached to the alley wall at the goal location, marked here with an asterisk. 
half as far as the chick. For half of each of these two groups, the cup alone moved. For the other half of each group, the chick's total visible environment moved, including the cup.

According to the closed-loop thesis, the experimental condition, in which the chick's visible environment is moved in the same direction and twice as far as the chick, would reverse the polarity of the loop's feedback, converting it from error-reducing negative feedback to errorincreasing positive feedback. Hence, the chick should be unable to consummate his approach responses. Instead, he should persistently chase the food cup away from himself, evincing the runaway behavior of a control loop subjected to positive feedback. Moving the food cup alone in this manner delimits the positive feedback to a small part of the visible environment, but since that part is central to the instrumental act, the reversal should impair performance. Moving either the food cup alone or the entire visible environment in the same direction and half as far as the chick would not reverse the polarity of feedback, and hence should not impair the chick's behavior. He would merely need to move farther than he normally would.

\section{METHOD}

\section{Summary}

The test alley was a long $(2.44 \mathrm{~m})$, narrow $(14 \mathrm{~cm})$, topless box. A frosted acetate window $3.8 \mathrm{~cm}$ high extended the length of the alley on each wall. The alley was transilluminated through one of these windows by a long $(2.44 \mathrm{~m})$ fluorescent tube. Through the other window, the "eyes" (photocells) of a closed-loop control mechanism tracked the silhouette of the moving chick and moved either a food cup or the chick's total visible environment in that same direction. In the latter case, a long $(78.7 \mathrm{~cm})$, narrow $(11.4 \mathrm{~cm})$, bottomless balsa wood box with its own frosted acetate windows was inserted into the alleyway surrounding the chick, which stood upon a plate glass mirror floor. A food cup was mounted inside this shell environment near one end just below one of the windows, with a piece of glitter tape attached directly above. The opposite end of the shell was papered with a Scotch plaid design to render it distinctive. When the shell environment was not being used, the Scotch plaid design was fixed to the corresponding end of the long alleyway, the food cup was mounted to a transparent railing extending down into the alley in the same manner as the cup-bearing wall of the shell, and the glitter tape was attached to the alley wall at the goal position, the one point in the alley where the positions of the chick and the food cup would coincide.

Each chick was administered 10 test trials on each of 10 days. Each started at one of four ordinal alley positions, with position 1 closest to the food cup $(7.6 \mathrm{~cm})$ and position 4 requiring the chick to walk $53.3 \mathrm{~cm}$. Each chick, initially, was started at position 1 and progressed to more distant positions only if he was consistently able to get to the food cup from his current starting position. On the final test day the tracking apparatus was disengaged and each chick was given another 10 trials with normal but novel feedback.

The four test conditions described in the introduction are illustrated in Figure 1.

\section{Subjects}

Forty Hyline-950 cockerel chicks, newly hatched, served as subjects. They were tested in four groups of 10 each.

\begin{abstract}
Apparatus
Home cage. Except for training and test trials, the chicks lived in $10.2 \times 19 \times 20.3 \mathrm{~cm}$ (height) hardware-cloth cages, one to a cage. Each cage contained a water tube and a food cup. These 10 individual cages were enclosed in an $89 \times 48.3 \times 27.9 \mathrm{~cm}$ (height) lightproof container. This container remained dark except for $5 \mathrm{~min}$ every hour during which the chicks could eat and drink. (Chicks apparently do not eat or drink in the dark [Schreck, 1958]). The container was illuminated internally by eight 7 -W light bulbs. The container was well ventilated, and the heat from these lights did not seem to disturb the chicks. The home cages allowed the chicks very limited visual and locomotor experiences.

Test apparatus. Figure 2 is a schematic diagram of this apparatus. The major part of the test apparatus was a straight alley, $2.44 \mathrm{~m}$ long, $14 \mathrm{~cm}$ wide, and $30.5 \mathrm{~cm}$ deep (inside measurements), painted neutral gray. The chicks walked on a false floor $11.4 \mathrm{~cm}$ above the bottom of the alley. There were two such floors, one $78.7 \mathrm{~cm}$
\end{abstract}

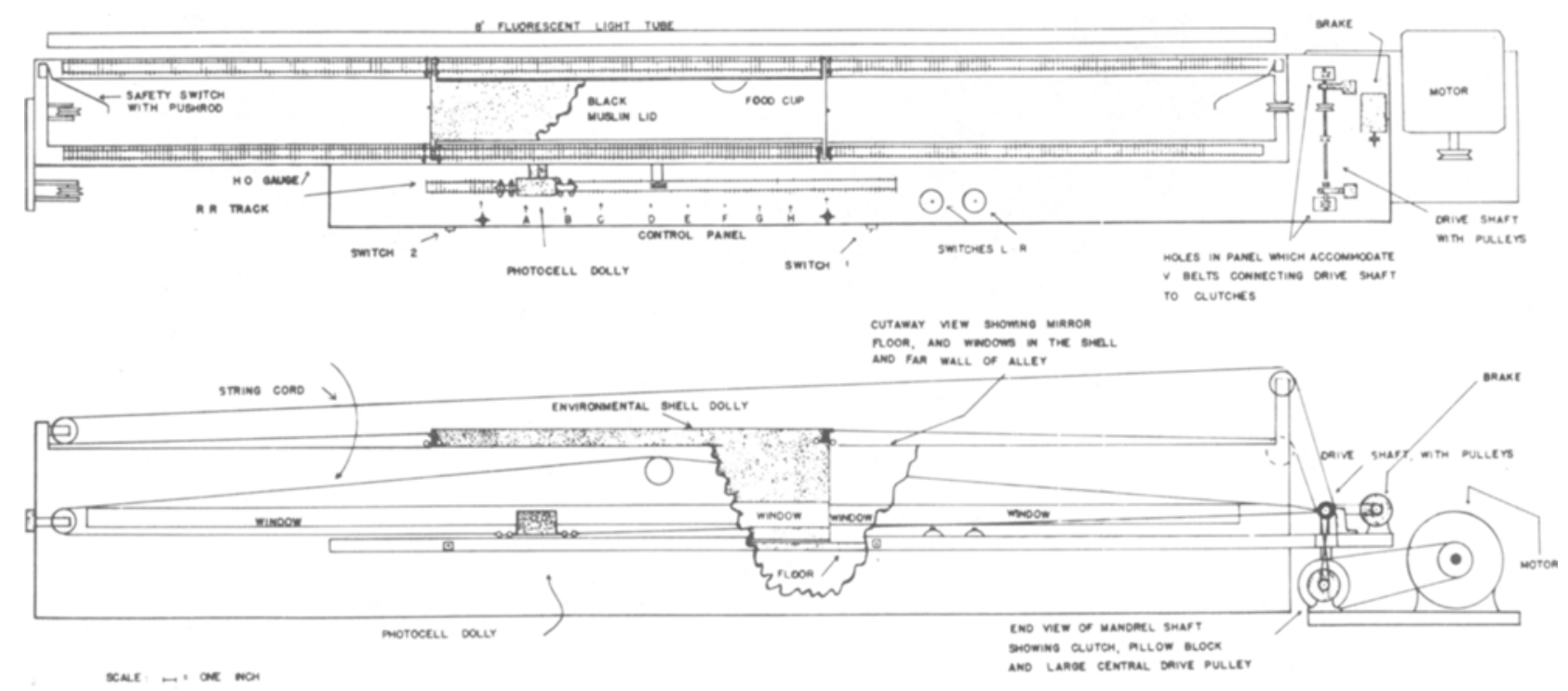

Figure 2. Top and side view of the test apparatus showing the environmental-shell dolly. 
long (short floor), and one $2.33 \mathrm{~m}$ long (full-length floor). Each of these floors was a plate glass mirror. Their respective uses are indicated below.

Along each side of the alley, centered $5.7 \mathrm{~cm}$ above the false floor, was a horizontal slit, $3.8 \mathrm{~cm}$ high, which extended almost the entire length of the alley. A strip of frosted acetate covered each of these windows from the inside of the alley. An instant-start fluorescent tube, $2.44 \mathrm{~m}$ long, was suspended outside the alley next to one of these windows, through which it illuminated the runway. On the outside of the opposite side of the alley, positioned $2.5 \mathrm{~cm}$ below the other window, was an HO-gauge railroad track. This track, $91.4 \mathrm{~cm}$ long, was centered at the midpoint of the overall alley length. A movable dolly, riding this track, accommodated two photoelectric cells, each $12.7 \mathrm{~mm}$ in diameter. These photocells were fixed about $1.6 \mathrm{~mm}$ apart, at the height of the windows, facing the fluorescent tube across the alley. A drive shaft propelled this dolly to and fro along the track. The photocells, in turn, activated this drive shaft to form a simple closed-loop tracking device.

The tracking device operated as follows. Two electromagnetic clutches were cantilevered on the opposite ends of a mandrel shaft. This shaft revolved continuously at $1,166 \mathrm{rpm}$, powered by a $1 / 4-\mathrm{hp}$ motor. A small v-belt linked the take-off shaft of each of these clutches to a drive shaft. One of these belts was twisted into the shape of a figure eight. Thus, when activated (one at a time), these clutches rotated the drive shaft in opposite directions. An electromagnetic brake was also linked to the drive shaft by a small v-belt. When activated, this brake prevented the drive shaft from rotating. A cord (linen string) connected the photocell dolly to the drive shaft via two free-wheeling pulleys. Rotation of the drive shaft moved the photocell dolly along its track. Conversely, the photocells, via a set of electrical relays, controlled the two clutches and the brake. If neither or both of the photocells saw light, the brake was activated and both clutches idled. If one, and only one, of the photocells saw light, the brake and one of the clutches idled while the other clutch was activated. For example, if only the north photocell was shadowed, the clutch propelling the photocell dolly north was activated. If only the south cell was shadowed, the dolly moved south. When a chick was placed in the alley in front of the photocells, he cast a shadow over both cells. If the chick moved either north or south, he shadowed only one cell, and the photocell dolly immediately followed his movement. Thus, the photocell dolly tracked the position of the chick within the alley.

Along the upper edge of the sides of the alley, and extending the length of the alley, were two additional tracks accommodating dollies that straddled the alley and extended down into the alley proper. There were two such dollies, one incorporating a shell environment, the other merely a railing.

The environmental shell was a gray balsa wood box, $21 \mathrm{~cm}$ high, $11.4 \mathrm{~cm}$ wide, and $78.7 \mathrm{~cm}$ long (inside measurements), with no floor and a hinged black muslin lid that served as a one-way screen. Along the two sides of this shell were two windows, comparable to those in the sides of the alley. They were $5.1 \mathrm{~cm}$ high and extended the entire length of the shell. They were covered from the inside by frosted acetate. When the shell dolly was positioned on the tracks, the shell extended into the alley just skirting the mirror floor, the two windows facing their alley counterparts. The environmental shell was used in conjunction with the full-length floor. This mirror floor reflected the shell suspended above it, so that it would appear to a chick within the shell as though the shell surrounded him on all six sides. A transparent food cup, approximately $5.1 \mathrm{~cm}$ wide, $2.5 \mathrm{~cm}$ high, and $2.5 \mathrm{~cm}$ deep, was fixed to the inside of the shell just below the window on the fluorescent-tube side, and $7.6 \mathrm{~cm}$ from the end of the shell nearest the drive shaft. Distinctive features were added to the inside of the shell to provide the chick with landmarks. A piece of glitter tape, $5.1 \mathrm{~cm}$ square, was attached to the wall above the food cup. The opposite end of the shell was wallpapered in a Scotch plaid design. Small tufts of cot- ton were attached to the inside of the shell to form four horizontal rows, one above and one below each of the two windows.

The railing dolly, in effect, was merely part of the wall of the shell dolly that supported the food cup. It consisted of a rectangular frame, fitted with wheels, that straddled the alley, and a transparent railing that extended down into the alley. The railing itself consisted of two widely spaced vertical shafts of Plexiglas (each $.3 \times 5.1 \times 21.6 \mathrm{~cm})$ with a strip of clear acetate $(5.1 \times 61 \mathrm{~cm})$ spanning the distance between the two vertical shafts, $2.5 \mathrm{~cm}$ above their lower extremities. This railing reduced the alley width to a usable $11.4 \mathrm{~cm}$, which was the inside width of the shell environment. A food cup, identical to the one mentioned above, was attached to the lower extremity of one of the vertical shafts of Plexiglas, that is, the one nearest the drive-shaft end of the alley. The railing dolly was used in conjunction with the short mirror floor $(78.7 \mathrm{~cm})$, which was positioned in the central third of the alley. The landmark features of the shell environment were attached to the inside of the alley itself when chicks were being tested with the transparent railing: The glitter tape was mounted on the wall to mark the goal position in the alley, where the chick and the food cup would coincide. Wallpaper covered the end of the alley opposite the drive shaft. The windows above and along the length of the short floor were bordered with cotton tufts. When the railing dolly was in use, a one-way-vision screen of black muslin was suspended horizontally about $15.2 \mathrm{~cm}$ above the alley, with a flap hanging down over the edge of the alley nearest the experimenter.

When in use, the shell (or railing) dolly was connected to the drive shaft with a linen cord. The drive-shaft pulley, around which this cord was wrapped, was either twice or half the diameter of the pulley for the photocell dolly; this resulted in the shell's (or the railing's) moving, respectively, twice or half the distance moved by the photocell dolly. (The shell-or railing-always moved in the same direction as the photocell dolly.) Two pulleys were used, one $1.9 \mathrm{~cm}$ and one $9.5 \mathrm{~mm}$ (outside diameter). When the negativefeedback groups were being tested, the small pulley moved the shell (or railing), and the large pulley moved the photocell dolly. When the positive-feedback groups were being tested, the two pulleys were switched. In the first case (negative feedback), the shell environment (or railing) moved in the same direction and half as far as the subject. In the second case (positive feedback), the shell environment (or railing) moved in the same direction and twice as far as the subject.

The apparatus had to be calibrated differently for the positiveand negative-feedback groups. When the negative-feedback groups were being tested, the shell (or railing) was first placed in the alley so that the food cup was aligned with the position marked $\mathrm{H}$ on the control panel (see Figure 2). The photocell dolly was also lined up with position $H$. The cords to the drive shaft were then made fast. Thereafter, the photocell dolly, the chick it tracked, and the food cup all came abreast only at position $H$. The goal position for the negative-feedback groups, therefore was, control panel postion $\mathrm{H}$.

When the positive-feedback groups were being tested, the apparatus was calibrated by aligning the food cup and the photocell dolly at control panel position A. Position A was, therefore, the goal position for the positive-feedback groups.

The stars on the control panel (Figure 2) indicate the limits of the chick's running space. For the railing groups, the stars indicate the two ends of the short floor, which served as cliff-type barriers. The chicks did not jump down from this short floor, except for a few times when they lost their balance at the edge of the floor. When the shell-environment groups were tested, a safety switch (a microswitch with a long pushrod) was mounted at each end of the alley. If a shell-environment subject reached either of the positions marked with a star, the shell activated one of these limit switches. The limit switch turned off the fluorescent tube that illuminated the alley and the photocells. When the light went off the 
shell halted immediately, and the chick, being in the dark, did likewise. In either case, when a chick jumped from the short floor or activated a safety switch, the alley was darkened, the timer (see below) was turned off, the chick was returned to his starting position for that trial, and the trial was resumed. This typically involved placing the chick closer to the goal position than he had just been.

Switches L and R (see Figure 2) were used to move the photocell dolly to the position at which a subject was going to be placed into the alley. Switch 1 was used to turn on the instant-start fluorescent tube and start a Standard Electric stop clock to measure response time. Switch 2 was used to stop this clock and immediately start a second Standard Electric timer to measure reward time. A 25-W red light bulb, suspended about $.91 \mathrm{~m}$ above the center of the test apparatus, illuminated the testing area.

\section{Procedure}

Altogether, there were four groups of 10 subjects each. The four experimental conditions were as follows: shell environmentpositive feedback $(\mathrm{S}+)$, shell environment-negative feedback $(\mathrm{S}-$ ), railing-positive feedback $(R+)$, and railing-negative feedback $(\mathrm{R}-)$. All of the chicks in a given group were tested at the same time, making it necessary to change the apparatus only three times during the experiment.

Each subject's home cage contained a water tube and food cup. Water was present in these cages at all times. Except during experimental deprivation periods, the food cup contained Purina Starter Feed (micro-mix). For $5 \mathrm{~min}$ out of every hour the lightproof box containing the 10 home cages was illuminated. Toward the end of the third day, the chicks were eating regularly during these 5-min feeding periods. On the evening of the third day, the food was removed from the cages, and the chicks were put on an overnight, 11-h deprivation schedule, which was maintained for the duration of the experiment. On the fourth and following days the chicks were trained (or tested) immediately after the deprivation period. After each training (or testing) session, food was placed in the home cages, to be removed later that evening.

Training. On the fourth day, each chick received 20 training trials. The apparatus was adjusted so that the cup was at the goal position. The tracking device, which normally moved the shell or railing, was inactive and the alley was illuminated. The chick was placed into the alley next to the food cup and was allowed to eat for several seconds. The food was the same as that in the home cages. The trials were spaced so that each chick in the group received one trial before any chick received a second trial, and so forth. The four blocks of 5 trials were separated by intervals of at least $1 \mathrm{~h}$. The purpose of this training was to familiarize the chicks with the apparatus and with eating from the food cup. Toward the end of this 20-trial period, all chicks would immediately begin to eat when placed next to the food cup. On the following day, each chick received 5 additional training trials before testing began, and from the day thereafter, received 1 training trial prior to the daily 10 test trials.

Testing. During testing, the food in the cup was moistened to form a paste. (During test trials, dry food would have spilled from the cup, necessitating interminable cleaning of the alley floor; the paste remained in the cup.) The chicks were adapted to this new food during the five training trials on the first test day.

During testing, the chicks were not always introduced to the alley at the same starting position, but initially began at a position near the food cup and progressed to more distant starting positions as their skill increased. This procedure was used to facilitate a foodgetting orientation and prevent superfluous exploratory behavior. There were four such starting positions, designated hereafter simply as starting positions $1,2,3$, and 4 . Starting position 1 was closest to the food cup; starting position 4 was the farthest from the food cup. For the positive-feedback groups, these four starting positions corresponded to control panel positions $B, D, F$, and $H$, respec- tively (see Figure 2). For the negative-feedback groups, the four starting positions corresponded to control panel positions F, E, C, and $A$, respectively. In both cases, the distances to the goal position from starting positions 4,3 , and 2 were $53.3 \mathrm{~cm}, 38.1 \mathrm{~cm}$, and $22.9 \mathrm{~cm}$, respectively. The distance from starting position 1 to the goal position differed for the two cases. In both cases, starting position 1 was $7.6 \mathrm{~cm}$ from the food cup itself. During the early test trials, when the chicks were required to recognize the food cup from a distance for the first time, the distance to the cup would presumably be much more crucial than the distance to the goal position in determining the duration of a response. In later trials, the converse would seem to hold. Inasmuch as the starting positions could not be matched in terms of both distance to the cup and distance to the goal position, the aforementioned compromise was adopted.

On the first test trial, the chick was placed into the darkened alley at starting position 1. Chicks tend to be inactive in the dark, and the subjects remained close to the position at which they had been introduced to the alley until the fluorescent tube that illuminated the alley was switched on. The light switch also started a clock. If the chick got to the food cup, that is, was in a position to stop and eat, within $1 \mathrm{~min}$, he was allowed to eat for $5 \mathrm{sec}$, the duration of his response was noted, and the trial was recorded as successful. If the chick did not reach the food cup within $1 \mathrm{~min}$, he was removed to his home cage at that time, a duration of $1 \mathrm{~min}$ was noted, and the trial was recorded as unsuccessful. If the chick performed successfully on four consecutive trials at starting position 1 , he was started on the following trial at position 2 . In this way he could advance finally to position 4 .

Each chick received 10 spaced test trials daily, each receiving one trial before any received a second trial. The chicks were tested for 10 consecutive days, that is, until they were 2 weeks old.

Normal environment test trials. On the final test day, each chick received an additional 10 trials in the apparatus with the tracking device turned off. For these trials the test environment was totally normal, although unfamiliar. During these trials, the food cup was set at control panel position $\mathrm{H}$, and the chicks were always introduced at position A, $53.3 \mathrm{~cm}$ distant. These normal environment test trials are hereafter referred to as NET trials, to distinguish them from the previously discussed test trials. Except for the aforementioned differences, the experimental procedures used during the NET trials were identical to those used during the previous test trials.

\section{RESULTS}

The performance of each of the four experimental groups is summarized in Table 1 in terms of three dependent measures: mean response duration per trial, percentage of trials successful, and mean starting position

Table 1 Summary of the Results

\begin{tabular}{|c|c|c|c|c|}
\hline \multirow[b]{2}{*}{ Dependent Variable } & \multicolumn{4}{|c|}{ Group } \\
\hline & $\mathbf{S}+$ & S- & $\mathbf{R}+$ & R- \\
\hline \multicolumn{5}{|c|}{ Test Trials } \\
\hline $\begin{array}{l}\text { Mean starting position } \\
\text { Mean response duration (in minutes) } \\
\text { Percentage of trials successful }\end{array}$ & $\begin{array}{l}1.5 \\
.87 \\
22\end{array}$ & $\begin{array}{l}4.3 \\
.16 \\
94\end{array}$ & $\begin{array}{l}2.8 \\
.80 \\
35\end{array}$ & $\begin{array}{l}4.5 \\
.06 \\
99\end{array}$ \\
\hline \multicolumn{5}{|c|}{ NET Trials } \\
\hline $\begin{array}{l}\text { Mean response duration (in minutes) } \\
\text { Percentage of trials successful }\end{array}$ & $\begin{array}{l}.14 \\
97\end{array}$ & $\begin{array}{l}.09 \\
96\end{array}$ & $\begin{array}{l}.05 \\
100\end{array}$ & $\begin{array}{r}.03 \\
100\end{array}$ \\
\hline
\end{tabular}

Note-Group S+: shell environment, positive feedback; Group S-: shell environment, negative feedback; Group $R+$ : railing environment, positive feedback; Group $\mathrm{R}-$ : railing environment, negative feedback. 


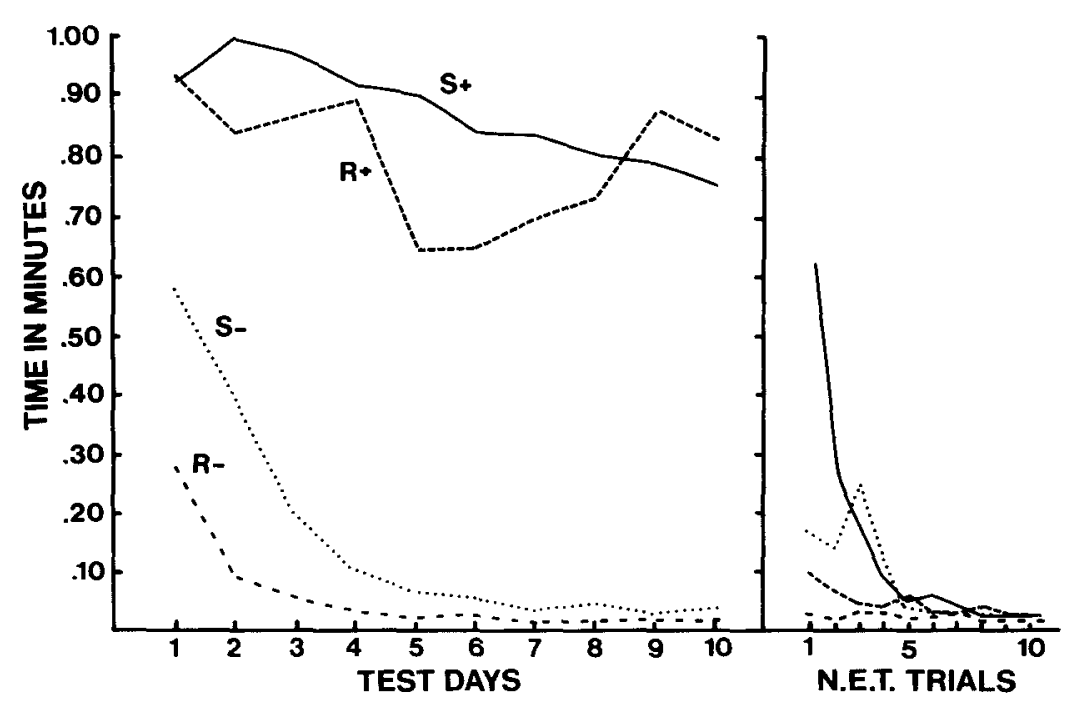

Figure 3. Daily mean response duration per trial for the two experimental groups $(S+$ and $\mathbf{R}+)$ and the two control groups $(S-$ and $\mathbf{R}-)$, expressed in minutes. The normal environment test (NET) performance is plotted on the right for each of the 10 NET trials.

per trial. The daily performance of individual chicks has been reported elsewhere (Hershberger, 1962). Chick No. 7 of Group R- died on Test Day 6; data from this subject are not included in these results.

The test trial performance of each of the positivefeedback groups was significantly inferior to the corresponding negative-feedback groups on all three indices. In no case was there any overlap in the two distributions. In contrast, there were no significant differences among the four groups on the NET trials.

The daily performance of each group is plotted in Figure 3 in terms of the mean response duration per trial, and in Figure 4 in terms of the mean number of successful trials per subject. A comparison of these two figures shows that these two indices of performance are nearly equivalent, indicating that the long response durations of the positive-feedback groups resulted principally from the frequent inability of these chicks to reach the food cup. The lengthy responses of these groups do not reflect slowness of movement. Indeed, some of the R+ chicks moved so rapidly that they frequently slipped and fell.

Figures 3 and 4 also show the performance of each group on the NET trials. The positive-feedback groups immediately and consistently performed better on these

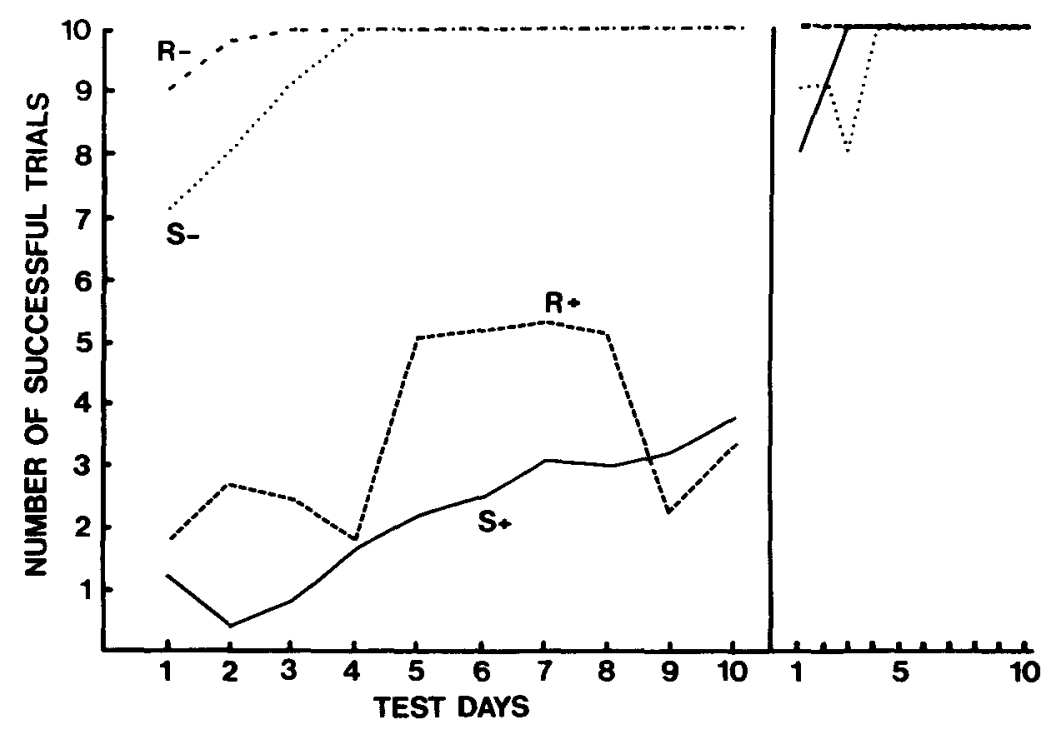

Figure 4. Daily mean number of successful trials per chick for each of the two experimental groups $(S+$ and $R+$ ) and the two control groups $(S-$ and $R-)$. The normal environment test (NET) performance is plotted on the right in terms of the proportion of chicks in each group that were successful on each of the 10 NET trials. 


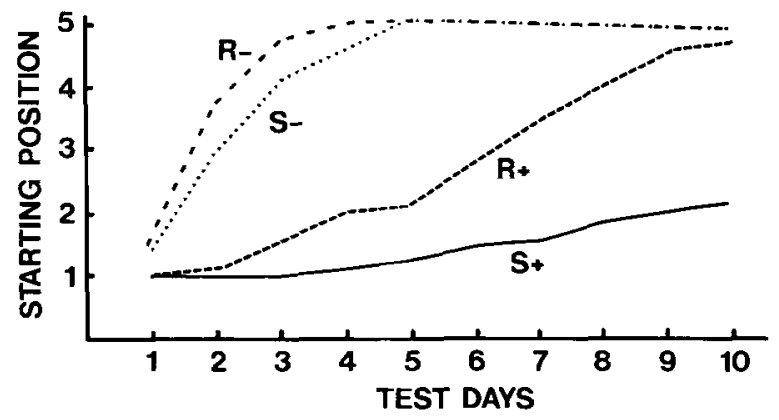

Figure 5. Daily mean starting position per trial for the two experimental groups (S+ and $R+$ ) and the two control groups (Sand $\mathbf{R}-$ ).

NET trials than they had on the test trials in the familiar abnormal environment. Furthermore, the negativefeedback groups showed only a temporary decline in performance during the NET trials.

In Figure 5, the daily performance of each group is plotted in terms of the mean starting position per trial. Subjects who passed the criterion of four consecutive successful trials at starting position 4 were subsequently scored as starting from a purely nominal position 5 , whereas they actually continued to be started at position 4 . Except for position 4, once a chick had passed the criterion at a starting position, he was never started there again, irrespective of his subsequent performance. Therefore, the curves in Figure 5 are monotonic, cumulative curves that do not reflect the fact (see Figures 3 and 4) that improvement in the performance of the $\mathrm{R}+$ chicks was a temporary thing, each chick first improved, then declined, improving and declining in his ability to reach the food cup. However, this measure does indicate that nearly every (all but 1) R+ chick, at one time or another, passed the criterion at starting position 4 . In contrast, half of the $\mathrm{S}+$ chicks were unable to pass the criterion even at starting position $1,7.6 \mathrm{~cm}$ from the food cup.

\section{DISCUSSION}

The present findings are in general agreement with Powers's thesis that organisms are closed-loop mechanisms that realize their intentions by means of negative feedback. According to the closed-loop thesis, the performance of the $\mathrm{S}+$ and $\mathrm{R}+$ groups should have been markedly inferior to that of the corresponding $\mathrm{S}-$ and $\mathrm{R}-$ groups, with the $\mathrm{S}+$ group showing the poorest performance of all, and the $S$ - and $R$ - groups performing very well and about equally. Such in fact was the case.

The chicks were examined shortly after hatching and therefore before they had had any appreciable locomotor experience in a normal environment. Also, the home cages in which the chicks lived during the experiment severely limited their locomotor experience within a normal environment. Yet the locomotor behavior of these chicks was strikingly and persistently inadequate in an environ- ment that reversed from the normal state of affairs the consequences of the chicks' locomotor activity. Even after the chicks had received extensive experience in the positive-feedback environment, their performance in that environment was inferior to their subsequent performance in a normal, though less familiar, environment (NET trials).

Furthermore, the polarity of feedback is the critical factor. That is, alteration of the feedback function seriously hindered the chicks only when the alteration amounted to an inversion of the normal function. The control subjects of the present experiment (Groups $\mathrm{R}-$ and $\mathrm{S}-$ ) performed quite well, although they were confronted with an abnormal (i.e., moving) environment.

Another finding of the present research is that altering the feedback function of a part (the railing) of the subject's environment is not as disruptive as altering the feedback from the total (shell) environment. This seems to be the case whether the altered feedback is positive or negative. However, there is an interaction effect between the polarity of feedback and the extent to which the environment has been altered. That is, the performance curves of the two negative-feedback groups are essentially identical in shape, whereas the curves of the two positivefeedback groups differ strikingly. (It should be noted here that the performance curves of Groups $\mathrm{S}+$ and $\mathrm{R}+$ are essentially identical in shape to those obtained from corresponding groups in a pilot experiment. The difference, therefore, appears to be replicable and not attributable to sampling error.)

The only appreciable difference between the performance curves of Groups $\mathrm{R}-$ and $\mathrm{S}$ - is the rate at which these curves approach an asymptote. This difference appears to be the result of different degrees of cautiousness on the part of the chicks in these two groups. The chicks were slightly more disconcerted by the movement of the shell than by the movement of the railing. The $S-$ chicks startled and emitted distress calls more frequently than did the R- chicks, particularly during the early trials. They were correspondingly more wary.

The differences between the positive-feedback groups were more complex. Initially, the performance of the R+ group was superior to that of the S+ group in terms of both mean response duration per trial (Figure 3) and mean number of successful trials per day (Figure 4). However, by Day 9 , Group $\mathrm{R}+$ had become inferior to Group $\mathrm{S}+$ on both measures. Each chick in the $R+$ group contributed to this performance decrement; that is, the performance of each chick in the $R+$ group first improved and then declined. This decrement appears to reflect the development of two conflicting intentions: to be at the food cup and to be at the glitter tape. Except for the railing dolly, the feedback function of the $\mathrm{R}+$ test environment was normal; that is, in closed-loop terms, feedback was negative. This would permit the $R+$ chicks to achieve various positions in the alley, including the goal position, via closedloop control. In other words, the chicks would move, relative to the alley, in the direction in which they intended 
to move. Thus, their task was not particularly different from an ordinary umweg problem, for they could directly approach and achieve the goal position in the alley (which was marked by a piece of glitter tape on the alley wall), just as in an ordinary umweg problem the subject directly approaches and goes around the end of a barrier (see Woodworth, 1938, p. 758). However, in the traditional umweg problem, the closer the subject is to the end of the barrier, the farther the subject is from the goal object. In the $R+$ test situation, the closer the chick was to the goal position, the closer he was to the goal object. Very likely, the closer the chick got to the glitter tape the more tempting the food cup became. In effect, the R+ test situation likely became a conflict situation with a point of equilibrium in the two intentions (to go toward the glitter tape, and to go toward the food cup), which occurred when the chick was at some point in the alley between his starting position and the goal position. At this position between two equally attractive goals, the chick vacillated in his intentions, attempting alternately to approach the food cup and the glitter tape. Although this novel conflict is of the double-approach type (Miller, 1959), it would be stable and would, hence, account for the observed performance decrement. (Bateson and Wainwright [1972, p. 282], using a similar apparatus to study imprinting in domestic chicks, considered such conflict " $a$ form of behavioral titration, since it measures the point at which a bird's readiness to approach one stimulus is balanced by its readiness to approach the other one.') Furthermore, the observed behavior of the individual chicks clearly warrants this interpretation. That is, each $\mathrm{R}+$ chick first learned to approach the goal position, marked by glitter tape, where he merely stopped, turned, and began to eat. Later, as his proficiency increased, he began, in anticipation, to turn prematurely. Once he had turned to the cup, the chick invariably chased it away, that is, evinced the runaway behavior of a closed loop subjected to positive feedback. Sometimes the chick would snatch a beakful of food as the cup receded; more often, he would get nothing. Then the chick would reverse his direction and start over. Once started, this pattern became typical of the chick's behavior, so that he did little more than run in a circle or an ellipse, chasing the food cup back and forth in the alley. Coincident with the development of this pattern of performance was an apparent change in the chick's perception of the situation. He began to treat the food cup as though it were prey that had to be outmaneuvered. For example, he would proceed slowly toward the goal position and away from the cup with an air of nonchalance (the chicks typically traveled in the direction they were facing), pecking with pretended interest at the alley wall, only to wheel abruptly with wings flapping in a desperate lunge at the food cup. Once a chick began to do this, he seemed to pay less attention to his position in the alley, and employed such tactics while quite distant from the goal position and thus from the cup itself. All in all, the chick's performance went from bad to worse.
Not only did Group $\mathrm{R}+$ perform more poorly than expected, but some of the chicks in Group S+ performed better than expected. Five of the S+ chicks did not progress beyond starting position 1 . As a group of 5 , their mean response duration per trial for the entire test period was $.94 \mathrm{~min}$, and they had a mean number of .9 successful trials per day. The more active of these chicks repeatedly chased the food cup to the point at which the shell activated the safety switch at the far end of the alley. This switch turned off the fluorescent tube, thereby interrupting the trial. The chick was replaced at his starting position, which was closer to the food cup, and the trial was continued. This was repeated as often as five times for a given chick on a given trial. Each of these 5 chicks dramatically evinced the runaway behavior predicted by the closed-loop thesis. However, in contrast to these 5 chicks, Chick No. 3 progressed to starting position 4 , was successful on all but 6 of the last 60 trials, and had a mean latency per trial on Test Day 10 of .16 min. Although his performance was inferior to that of the negative-feedback subjects, Chick No. 3 of Group S+ performed quite well, at least better than one might expect of a closed-loop control system confronted with extensive positive feedback.

The explanation for the exceptional performance of Chick No. 3 is to be found in the fact that the positive feedback experimentally induced in the present study was entirely exteroceptive (principally visual) in nature. Kinesthesis and the so-called position sensations were undisturbed, allowing a chick to execute stereotyped patterns of movements while ignoring the visible environment. This is exactly what Chick No. 3 appeared to do. This chick's most difficult task was keeping his eye off the food cup. The cup was disruptive only if the chick looked at it, just as a falsely lettered keyboard disrupts a typist only if he or she reads it. Chick No. 3 locomoted in a peculiar fashion shared only by Chick No. 6, also of Group $S+$. Chick No. 3 faced the cup side of the shell and moved by sidestepping. (Since pirouette-like motions were visually undisturbed, a chick could orient itself radially within the alleyway by means of negative feedback.) He stood tall, with head up and neck stretched, as though looking at the alley wall above the translucent window. As was mentioned above, the food cup was mounted below this window, but a piece of glitter tape was attached above the window directly over the cup. Chick No. 3 appeared to use this glitter tape, not as a goal to be approached, but as a sign to stop his stereotyped pattern of egocentric movements. That is, he sidestepped to his left until the glitter tape appeared directly in front of him. He then lowered his head and ate from the cup. As long as his head was down, Chick No. 3 behaved no differently from the other $\mathrm{S}+$ subjects. If he stopped too soon or too late and lowered his head, he was as unsuccessful as the other chicks in approaching the cup; that is, he chased it away. However, unlike the others, he would soon give up the chase and revert to his stereotyped pattern of movements. Because he ignored the cup, he sometimes sidestepped right by the cup, or stood prancing in front of 
the cup, facing the glitter tape in an attitude of indecision for several seconds before lowering his head.

It is interesting that as Chick No. 3 executed his stereotyped movements he faced a side, rather than an end, of the alleyway. The apparent reason for this is twofold: First, in order to properly limit the duration of his stereotyped movements, he had to discern when the midline of his body became aligned with the food cup. Second, the median sagittal planes of a chick's head and body are coincident, whereas the corresponding median frontal planes are not. Hence, stopping as his head became aligned with the glitter tape would serve to align Chick No. 3's body with the food cup if, but only if, he stood sideways in the alley, which consequently, he did.

Another chick (No. 6), whose performance was somewhat similar to that of Chick No. 3, frequently passed by the cup. On several occasions, he was struck by the cup and developed a fear of it. On later trials, he was unable to control his stepping, which became a futile flight response. He became less and less able to stop, so that he almost always passed the cup and activated the safety switch at that end of the alley. He usually did this several times on every trial; at a maximum, he did so seven times on Trial 99. Just as the $\mathbf{5}$ chicks mentioned above could not consummate their approach responses, Chick No. 6 was unable to consummate an avoidance response.

According to Powers's closed-loop thesis, the visual approach response is an intended visual perception that is realized automatically by closed-loop control. The notion that overt behaviors are perceptual rather than effector events is, perhaps, strange to most contemporary psychologists, but it is not a novel idea. In his Principles of Psychology, William James (1890) wrote

\begin{abstract}
We may consequently set it down as certain that, whether or no there be anything else in mind at the moment when we consciously will a certain act, a mental conception made up of memory-images of these sensations, defining which special act it is, must be there .... I trust that I have now made clear what that "idea of a movement" is which must precede it in order that it be voluntary. It is not the thought of the innervation which the movement requires. It is the anticipation of the movement's sensible effects, resident or remote, and sometimes very remote indeed. (Vol. 2, pp. 492, 521)
\end{abstract}

More recently, Gibson (1966, pp. 160-162) described the visual approach response in just such terms, that is, in terms of visual "sensations, defining which special act it is." To paraphrase Gibson, the visual approach response may be defined as a centrifugal optical flow of the whole array of ambient light across the surface of the retina away from the retinal point coinciding with the direction of locomotion. The form in the array on which the focus of expansion is centered corresponds to the place toward which the animal is proceeding. In other words, visually approaching a goal means optically expanding that part of the optic array that specifies that goal. Gibson supposed that the animal "governs the muscles of locomotion" $(1966$, p. 162) to make the goal loom up. However, the present data, in keeping with James's observation and Powers's thesis, indicate that the chick need only, or rather can only, select the perceptual form (goal) to be optically expanded, and that the muscles of locomotion participate automatically in the closed-loop mediation of that intended perception. That is, the chick controls not his muscles but his visual environment: He may select which visual form to approach, but he is unable to select whatever muscular activity proves necessary to achieve that end. The muscular activity is itself a (virtually) direct function of the signed difference between the desired and actual visual afference, such that feedback is normally negative and the selected visual form looms up. When the spatial polarity of the environment is reversed, as in the present experiment, positive feedback obtains and the chick's selected visual form optically contracts as he chases helplessly after it in a futile runaway behavior.

All in all, the present results provide convincing evidence that it is possible to disable a naive organism simply by reversing the spatial polarity of its environmental feedback. The closed-loop thesis from which this implication derives is thus confirmed, and the theoretical viewpoint Powers (1973a, 1973b, 1978; Powers, Clark, \& McFarland, 1960a, 1960b) has consistently championed is upheld.

Finally, in fairness to the closed-loop thesis, it must be noted that systems incorporating self-reorganizing processes such as those described in Ashby's (1952) classic Design for a Brain are capable, in principle, of correcting or compensating for polarity reversals such as those encountered by the present subjects. Furthermore, since Powers's general feedback theory incorporates such putative processes, his model implies that it is possible that even the present subjects would eventually have become reorganized (i.e., feedback would again be negative or error reducing), provided only that they "did not die first" (Powers, 1973a, p. 188). However, selfreorganization is rendered an academic consideration in the present case by virtue of its absence. At best, the chicks in the present experimental conditions reorganized their task, rather than themselves. Even the very best, most successful experimental subject (No. 3), whenever he put his head down, evinced the runaway behavior characteristic of a closed-loop system subjected to positive feedback.

\section{REFERENCES}

Ashby, W. R. (1952). Design for a brain. New York: Wiley.

Bateson, P. P. G., \& Wainwright, A. A. P. (1972). The effects of prior exposure to light on the imprinting process in domestic chicks. Behavior, 42, 279-290.

CARROLL, L. (1926). Through the looking-glass and what Alice found there. New York: MacMillan. (Original work published 1898)

GiBson, J. J. (1966). The senses considered as perceptual systems. Boston: Houghton Mifflin.

Hershberger, W. A. (1962). Experimentally induced positive feedback in locomotor behavior. Dissertation Abstracts, 23, 2219-2220. (University Microfilms No. 62-6276)

JAMES, W. (1890). The principles of psychology (Vol. 2). New York: Henry Holt. 
MiLLER, N. E. (1959). Liberalization of basic S-R concepts: Extensions to conflict behavior, motivation, and social learning. In S. Koch (Ed.), Psychology, a study of a science (Vol. 2). New York: McGraw-Hill. Powers, W. T. (1973a). Behavior: The control of perception. Chicago: Aldine.

POWERS, W. T. (1973b). Feedback: Beyond behaviorism. Science, 179, 351-356.

PowERs, W. T. (1978). Quantitative analysis of purposive systems: Some spadework at the foundations of scientific psychology. Psychological Review, 85, 417-435.

Powers, W. T., Clark, R. K., \& McFarland, R. L. (1960a). A general feedback theory of human behavior: Part I. Journal of Perceptual \& Motor Skills, 11(Suppl. 1-VII), 71-88.

Powers, W. T., Clark, R. K., \& McFarland, R. L. (1960b). A general feedback theory of human behavior: Part II. Journal of Perceptual \& Motor Skills, 11(Suppl. 3-VII), 309-323.
SCHRECK, P. K. (1958). A study of the development of eating in chicks. Unpublished master's thesis, University of Colorado, Boulder.

SMITH, K. U., \& MolitoR, K. (1969). Adaptation to reversal of retinal feedback of eye movements. Journal of Motor Behavior, 1, 69-87. SPERRY, R. W. (1951). Mechanisms of neural maturation. In S. S. Stevens (Ed.), Handbook of experimental psychology. New York: Wiley.

WoODWORTH, R. S. (1938). Experimental psychology. New York: Henry Holt.

von Holst, E., \& MitTELSTAEdt, H. (1950). Das Reafferenzprinzip. Naturwissenshaften, 37, 464-476.

YARBUS, A. L. (1962). Eye movements and vision. (Trans. by B. Haigh) New York: Plenum Press.

(Manuscript received April 23, 1986; revision accepted for publication August 26, 1986.) 